\title{
A Single Low Dose of Eribulin Regressed a Highly Aggressive Triple-negative Breast Cancer in a Patient-derived Orthotopic Xenograft Model
}

\author{
HYE IN LIM ${ }^{1,2,3}$, JUN YAMAMOTO ${ }^{1,2}$, SACHIKO INUBUSHI $^{1,2}$, HIROTO NISHINO $^{1,2}$, YOSHIHIKO TASHIRO $^{1,2}$, \\ NORIHIKO SUGISAWA ${ }^{1,2}$, QUINHONG HAN ${ }^{1}$, YU SUN ${ }^{1,2}$, HEE JUN CHOI ${ }^{3}$, SEOK JIN NAM ${ }^{4}$, MOON BO KIM ${ }^{5}$, \\ JI SUN LEE ${ }^{5}$, CHIHIRO HOZUMI ${ }^{6}$, MICHAEL BOUVET ${ }^{2}$, SHREE RAM SINGH $^{7}$ and ROBERT M. HOFFMAN ${ }^{1,2}$ \\ ${ }^{1}$ AntiCancer Inc, San Diego, CA, U.S.A.; \\ ${ }^{2}$ Department of Surgery, University of California, San Diego, CA, U.S.A.; \\ ${ }^{3}$ Department of Surgery, Samsung Changwon Hospital, \\ Sungkyunkwan University School of Medicine, Changwon, Republic of Korea; \\ ${ }^{4}$ Division of Breast Surgery, Department of Surgery, Samsung Medical Center, \\ Sungkyunkwan University School of Medicine, Seoul, Republic of Korea; \\ ${ }^{5}$ MetaBio, Inc., Seoul, Republic of Korea; \\ ${ }^{6}$ AntiCancer Japan Inc, Narita, Japan; \\ ${ }^{7}$ Basic Research Laboratory, National Cancer Institute, Frederick, MD, U.S.A.
}

\begin{abstract}
Background/Aim: In the present study, the breast cancer patient-derived orthotopic xenograft (PDOX) model was used to identify an effective drug for a highly aggressive triple negative breast cancer (TNBC). Materials and Methods: The TNBC tumor from a patient was implanted in the right 4th inguinal mammary fat pad of nude mice to establish a PDOX model. Three weeks later, 19 mice were randomized into the untreated-control group $(n=10)$ and the eribulin treatment group ( $n=9$, eribulin, $0.3 \mathrm{mg} / \mathrm{kg}$, i.p., day 1). Results: On day 8 , eribulin significantly inhibited tumor volume compared to the control group $(p<0.01)$. Eribulin regressed tumors in 3 mice $(33.3 \%)$ and apparently eradicated them in 6 mice (66.7\%). At day 14, tumor regrowth was observed in 2 mice of the eribulin group, which was undetectable on day 8 . However, $44.4 \%$ (4 out of 9) of the mice in the eribulin group were tumor-free on day 14. Conclusion: A single low-dose eribulin was efficacious
\end{abstract}

This article is freely accessible online.

Correspondence to: Robert M. Hoffman, Ph.D., AntiCancer Inc, 7917 Ostrow St, San Diego, CA, 92111, U.S.A. Tel: +1 8586542555 , Fax: +1 8582684175, e-mail: all@anticancer.com; Shree Ram Singh, Ph.D., Basic Research Laboratory, National Cancer Institute, Frederick, MD, 21702, U.S.A. Tel: +1 3018467331, e-mail: singhshr@mail.nih.gov

Key Words: Eribulin, PDOX, patient-derived orthotopic xenograft, patient-derived xenograft, PDX, TNBC, triple-negative breast cancer. on a highly aggressive TNBC. The breast cancer PDOX model can be used to identify highly effective drugs for TNBC.

Between 10 20\% of breast cancer patients are diagnosed with triple negative breast cancer (TNBC) based on the lack of estrogen receptor (ER), progesterone receptor (PR) and human epidermal growth factor receptor 2 (HER-2) (1). Triple negative breast cancer is treated with chemotherapy and/or radiotherapy after surgery, but has a poor prognosis despite chemotherapy, such as anthracyclines and taxanes, and is considered a recalcitrant disease with poor survival $(2,3)$.

Eribulin is a non-taxane, synthetic microtubule-dynamics inhibitor with antimitotic activity. Eribulin binds microtubule ends to prevent microtubule polymerization, blocks the cell cycle at the $\mathrm{G}_{2} / \mathrm{M}$ cell-cycle phase, and causes apoptosis (4). Eribulin also affects tumor vasculature remodeling, which increases vascular perfusion, reduces hypoxia, reverses epithelial-to-mesenchymal transition (EMT) and decreases migration ability and invasion (5-7). Recently, Eribulin has been used for patients with metastatic breast cancer since it showed increased overall survival in the EMBRACE trial (8).

Patient-derived orthotopic xenograft (PDOX) models of immunodeficient mice can recapitulate the histopathologic/ molecular characteristics of the primary tumor $(9,10)$ and can be used to screen multiple chemotherapeutics for individual treatment. Our laboratory developed the patient-derived orthotopic xenograft (PDOX) model of breast cancer in nude mice and described the orthotopic growth and metastases to the lung of breast cancer in 1993 (11). 
In the present study, we established a PDOX nude-mouse model of a highly aggressive TNBC and evaluated the efficacy of eribulin using this model.

\section{Materials and Methods}

Mice. Athymic nu/nu nude female mice (AntiCancer Inc., San Diego, CA, USA), 4-6 weeks old, were used in this study. Animals were housed in a barrier facility on a high efficiency particulate arrestance (HEPA)-filtered rack under standard conditions of 12hour light/dark cycles. The animals were fed an autoclaved laboratory rodent diet. All animal studies were conducted according to an AntiCancer Institutional Animal Care and Use Committee (IACUC)-protocol specifically approved for this study and in accordance with the principles and procedures outlined in the National Institute of Health Guide for the Care and Use of Animals under Assurance Number A3873-1. To minimize any suffering of the animals, anesthesia and analgesics were used for all surgical experiments. Animals were anesthetized by subcutaneous injection of a $0.02 \mathrm{ml}$ solution of $20 \mathrm{mg} / \mathrm{kg}$ ketamine, $15.2 \mathrm{mg} / \mathrm{kg}$ xylazine, and $0.48 \mathrm{mg} / \mathrm{kg}$ acepromazine maleate. The response of animals during surgery was monitored to ensure adequate depth of anesthesia $(9,10)$.

Patient-derived TNBC and establishment of PDOX. A 74-year-old female patient was diagnosed with invasive ductal carcinoma in the right breast. She underwent breast-conserving surgery with sentinel lymph node biopsy in the Department of Surgery, Samsung Medical Center (SMC), Seoul, Korea. The tumor size was $2.4 \mathrm{~cm}$ and nodal status was N0. Histologic grade was 3 . ER/PR/HER2 was negative and the Ki-67 value was $80.35 \%$. Written informed consent was obtained from the patient, and the Institutional Review Board (IRB) of SMC approved this experiment. Fresh patient-derived tumor tissue samples were immediately transported to the laboratory at MetaBio Inc. on ice. The samples were cut into $3 \sim 4 \mathrm{~mm}^{3}$ size fragments and implanted subcutaneously into nude mice. After subcutaneously-grown tumors reached $10 \mathrm{~mm}$ in diameter, they were harvested and cut into $2 \sim 3 \mathrm{~mm}^{3}$ size fragments. The tumor fragments were implanted in the right 4th inguinal mammary fat pad by surgical orthotopic implantation (SOI) to establish the PDOX model. The wound was closed with 7-0 nylon suture (11).

Treatment dose and schedule. Three weeks after SOI, the TNBC PDOX mouse models were randomized into two groups of nine to ten mice each: $\mathrm{G} 1$, untreated control $(\mathrm{n}=10) ; \mathrm{G} 2$, eribulin $(\mathrm{n}=9,0.3$ $\mathrm{mg} / \mathrm{kg}$, i.p., day 1). And then mice were observed for two weeks.

Tumor length, width, and mouse body weight were measured twice a week. Tumor volume was calculated with the following formula: Tumor volume $\left(\mathrm{mm}^{3}\right)=$ length $(\mathrm{mm}) \times$ width $(\mathrm{mm}) \times$ width $(\mathrm{mm}) \times 1 / 2$. Mice in the control group were sacrificed on day 8 and in the eribulin group on day 14 .

Statistical analyses. All statistical analyses were performed with $\mathrm{R}$ ver. 3.6.1 (R foundation, Vienna, Austria). Significant differences were determined using the Student's $t$-test. Graphs show the mean tumor volume and number of mice, and error bars represent standard deviation. A probability value of $p<0.05$ was defined as statistically significant.

\section{Results}

On day 8, 6 out of 10 mice in the control group had tumors larger than $3000 \mathrm{~mm}^{3}$ with a mean tumor volume of 3156.33 $\mathrm{mm}^{3}$. In contrast to the control group, the mean tumor volume of the eribulin group was $19.1 \mathrm{~mm}^{3}$ ( $p<0.01$, Figure 1). All tumors either regressed or disappeared in the eribulin group on day 8 (Figure 2). Tumors regressed in 3 mice $(33.3 \%$ ) and disappeared in the other 6 mice $(66.7 \%)$. On day $14,44.4 \%$ of the mice (4 out of 9) in the eribulin group still were without tumors. There was no statistically significant difference in body weight between the two groups on day 0 and day 4 . But on day 8 , there was a statistically significant difference on body weight that may be the result of differences in the tumor burden between the two groups (Figure 3). Histology did not show a difference between the tumors of the control group and the regrown tumors of the eribulin group (Figure 4).

\section{Discussion}

Eribulin has been previously shown to be efficacious at doses ranging from $0.1-2 \mathrm{mg} / \mathrm{kg}$, once to thrice a week in several in vivo studies with tumors derived from cancer cell lines $(4,12,13)$.

The present study has important implications since it demonstrated the efficacy of eribulin on a highly aggressive TNBC in a PDOX model by showing tumor regression and disappearance with a single low-dose eribulin.

Eribulin showed an improvement in overall survival (OS) compared with available cytotoxic therapy in patients with heavily pretreated metastatic breast cancer in the EMBRACE trial (8).

Another Phase III trial compared eribulin with capecitabine in metastatic breast cancer. There was a significant survival advantage with eribulin over capecitabine among breast cancer patients with HER2-negative breast cancer as well as TNBC (14). Based on these results, eribulin is used for the treatment of patients with metastatic breast cancer.

In TNBC, pathologic complete response (pCR) at the time of surgery is a favorable prognostic factor correlated with improved disease outcomes. The efficacy of eribulin as neoadjuvant treatment was studied only to a limited extent and some results were disappointing. Other clinical trials have not shown significantly improved efficacy of neoadjuvant eribulin over standard therapies $(15,16)$. But eribulin is still an attractive drug because its toxicity profile compares favorably with taxanes, and also avoids the risk of late toxicities associated with anthracyclines (17).

In the present study, the patient's tumor was growing rapidly compared with previously reported tumors from breast cancer cell line (18). It only took four weeks to reach a $3000 \mathrm{~mm}^{3}$ tumor volume in the control mice and we could get important information about the aggressiveness of this 


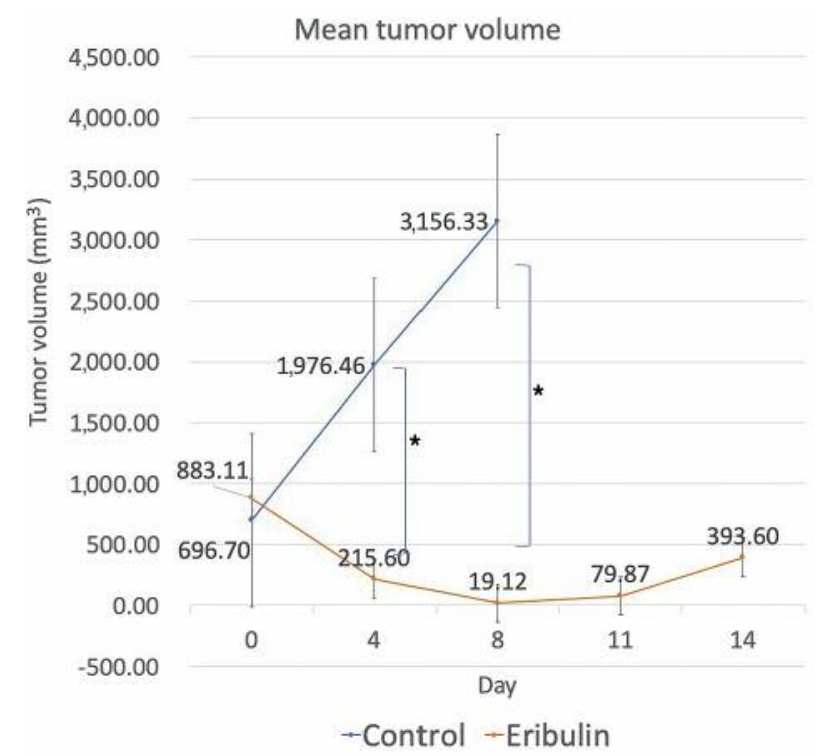

Figure 1. Tumor volume. TNBC tumors were implanted by surgical orthotopic implantation (SOI) in the right 4th inguinal mammary fat pad. Chemotherapy started. Resulting tumors were measured with calipers $(* p<0.01)$.

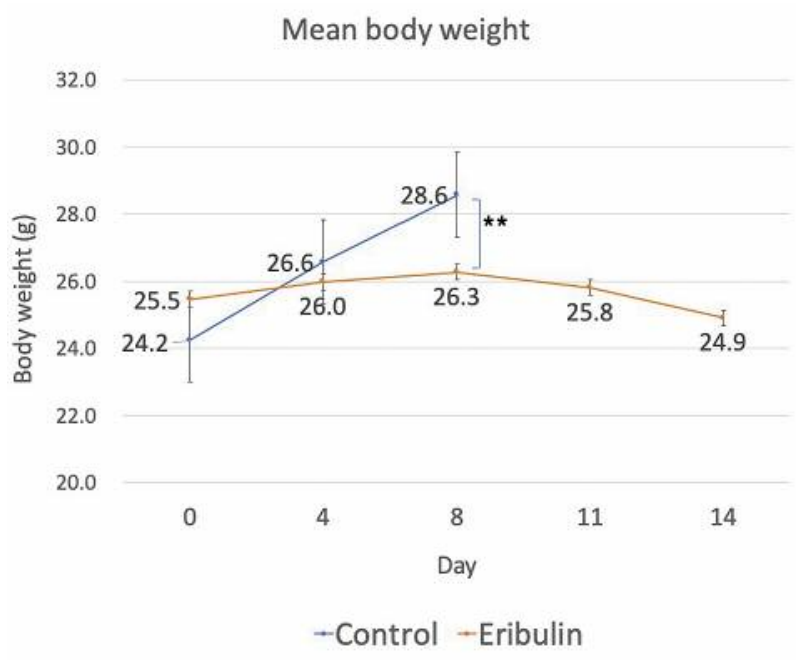

Figure 3. Mean body weight. Body weight was measured twice a week $(* * p<0.05)$.

tumor by establishing and using a PDOX model of the patient's tumor. The breast cancer PDOX model was developed by our laboratory in 1993 (11) and it took another 18 years until another laboratory published on a breast cancer PDOX model, claiming novelty for their study (18).

In conclusion, eribulin regressed a highly aggressive TNBC in the PDOX model. In this study, the PDOX model was successfully used to demonstrate that a single low-dose eribulin was effective against TNBC and this result suggested the potential of eribulin as a treatment for TNBC.

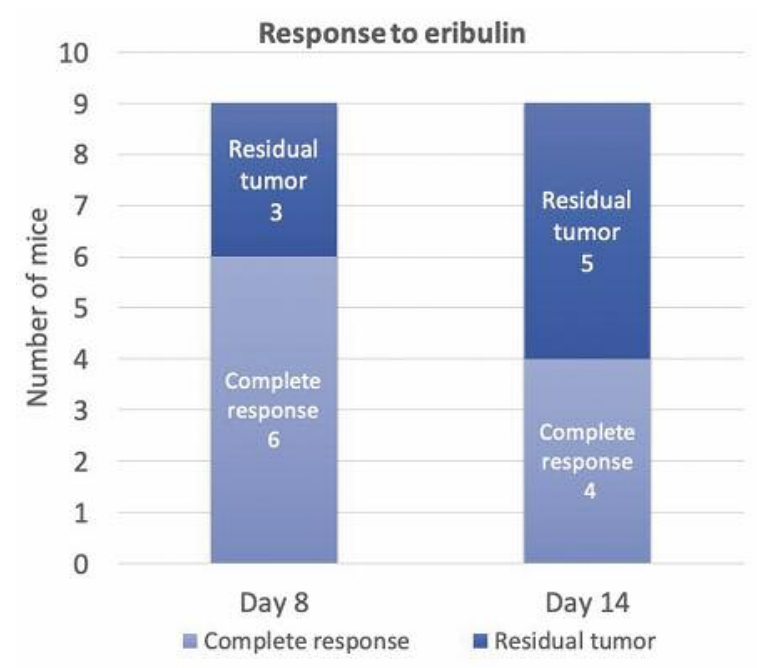

Figure 2. Tumor regression in the eribulin group. Presence of tumor was determined by tumor volume measurement and palpation.
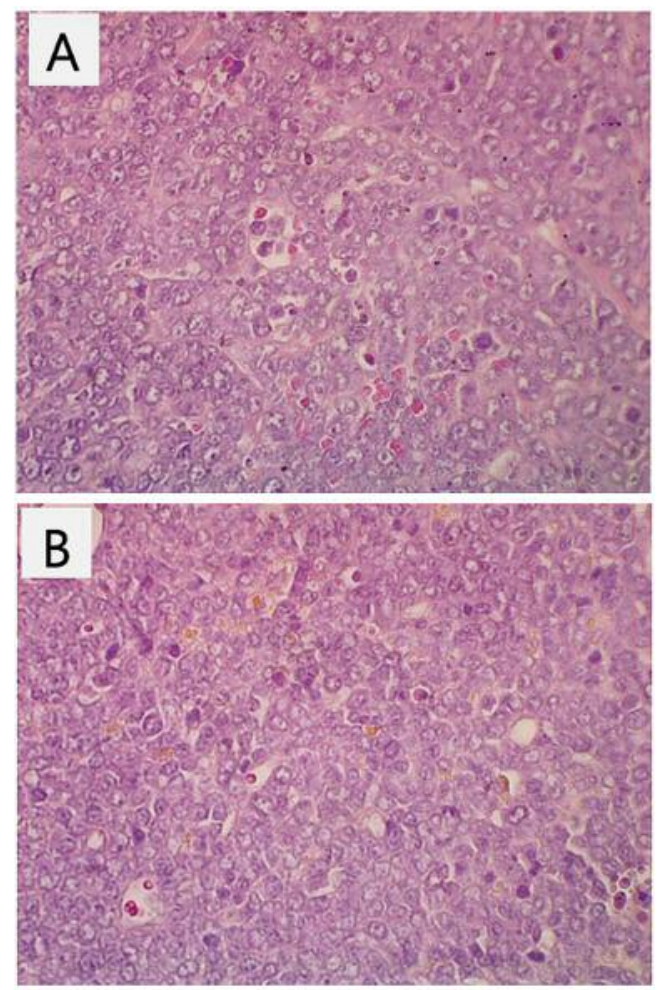

Figure 4. Histology of PDOX TNBC. Hematoxylin and eosin $(H \& E)$ staining of the untreated control PDOX tumor $(A)$ and the eribulintreated PDOX tumor (B).

Orthotopic models of cancer represent clinical cancer, unlike subcutaneous tumor models (19-21). Future experiments will label the TNBC PDOX with fluorescent proteins in order to visualize micro-metastasis (22). 


\section{Conflicts of Interest}

AntiCancer Inc. uses PDOX models for contract research. HIL, JY, SI, HN, YT, NS, QH, YS and RMH are or were unsalaried associates of AntiCancer Inc. There are no other competing financial interests.

\section{Authors' Contributions}

Conception and design: HIL and RMH. Acquisition of data: HIL, JY, SI, HN, YT, NS, QH, YS, and RMH. Analysis and interpretation of data: HIL, JY, SI, HN, YT, NS, QH, YS, HJC, SJN, MBK, JSL, $\mathrm{CH}, \mathrm{MB}, \mathrm{SRS}$, and RMH. Writing, review, and/or revision of the manuscript: HIL, RMH, and SRS.

\section{Acknowledgements}

This paper is dedicated to the memory of A. R. Moossa, M.D., Sun Lee, M.D., Professor Li Jiaxi, and Masaki Kitajima, MD.

\section{References}

1 Lin NU, Vanderplas A, Hughes ME, Theriault RL, Edge SB, Wong YN, Blayney DW, Niland JC, Winer EP and Weeks JC: Clinicopathologic features, patterns of recurrence, and survival among women with triple-negative breast cancer in the National Comprehensive Cancer Network. Cancer 118(22): 5463-5472, 2012. PMID: 22544643. DOI: $10.1002 /$ cncr.27581

2 Carey LA, Perou CM, Livasy CA, Dressler LG, Cowan D, Conway K, Karaca G, Troester MA, Tse CK, Edmiston S, Deming SL, Geradts J, Cheang MC, Nielsen TO, Moorman PG, Earp HS and Millikan RC: Race, breast cancer subtypes, and survival in the Carolina Breast Cancer Study. JAMA 295(21): 2492-2502, 2006. PMID: 16757721. DOI: 10.1001/jama.295.21.2492

3 Dent R, Trudeau M, Pritchard KI, Hanna WM, Kahn HK, Sawka CA, Lickley LA, Rawlinson E, Sun P and Narod SA: Triplenegative breast cancer: clinical features and patterns of recurrence. Clin Cancer Res 13(15 Pt 1): 4429-4434, 2007. PMID: 17671126. DOI: 10.1158/1078-0432.CCR-06-3045

4 Towle MJ, Salvato KA, Budrow J, Wels BF, Kuznetsov G, Aalfs KK, Welsh S, Zheng W, Seletsky BM, Palme MH, Habgood GJ, Singer LA, Dipietro LV, Wang Y, Chen JJ, Quincy DA, Davis A, Yoshimatsu K, Kishi Y, Yu MJ and Littlefield BA: In vitro and in vivo anticancer activities of synthetic macrocyclic ketone analogues of halichondrin B. Cancer Res 261(3): 1013-1021, 2001. PMID: 11221827

5 Garrone O, Miraglio E, Vandone AM, Vanella P, Lingua D and Merlano MC: Eribulin in advanced breast cancer: safety, efficacy and new perspectives. Future Oncol 13(30): 2759-2769, 2017. PMID: 29219017. DOI: 10.2217/fon-2017-0283

6 Funahashi Y, Okamoto K, Adachi Y, Semba T, Uesugi M, Ozawa Y, Tohyama O, Uehara T, Kimura T, Watanabe H, Asano M, Kawano S, Tizon X, McCracken PJ, Matsui J, Aoshima K, Nomoto $\mathrm{K}$ and Oda $\mathrm{Y}$ : Eribulin mesylate reduces tumor microenvironment abnormality by vascular remodeling in preclinical human breast cancer models. Cancer Sci 105(10): 1334-1342, 2014. PMID: 25060424. DOI: 10.1111/cas.12488

7 Cortes J, Schoffski P and Littlefield BA: Multiple modes of action of eribulin mesylate: Emerging data and clinical implications. Cancer Treat Rev 70: 190-198, 2018. PMID: 30243063. DOI: $10.1016 /$ j.ctrv.2018.08.008

8 Cortes J, O'Shaughnessy J, Loesch D, Blum JL, Vahdat LT, Petrakova K, Chollet P, Manikas A, Diéras V, Delozier T, Vladimirov V, Cardoso F, Koh H, Bougnoux P, Dutcus CE, Seegobin S, Mir D, Meneses N, Wanders J, Twelves C and EMBRACE (Eisai Metastatic Breast Cancer Study Assessing Physician's Choice Versus E7389) Investigators: Eribulin monotherapy versus treatment of physician's choice in patients with metastatic breast cancer (EMBRACE): a phase 3 open-label randomised study. Lancet 377(9769): 914-923, 2011. PMID: 21376385. DOI: 10.1016/S0140-6736(11)60070-6

9 Miyake K, Kawaguchi K, Kiyuna T, Miyake M, Igarashi K, Zhang Z, Murakami T, Li Y, Nelson SD, Elliott I, Russell T, Singh A, Hiroshima Y, Momiyama M, Matsuyama R, Chishima T, Endo I, Eilber FC and Hoffman RM: Regorafenib regresses an imatinib-resistant recurrent gastrointestinal stromal tumor (GIST) with a mutation in exons 11 and 17 of c-kit in a patientderived orthotopic xenograft (PDOX) nude mouse model. Cell Cycle 17(6): 722-727, 2018. PMID: 29334307. DOI: 10.1080/ 15384101.2017.1423223

10 Miyake K, Higuchi T, Oshiro H, Zhang Z, Sugisawa N, Park JH, Razmjooei S, Katsuya Y, Barangi M, Li Y, Nelson SD, Murakami T, Homma Y, Hiroshima Y, Matsuyama R, Bouvet M, Chawla SP, Singh SR, Endo I and Hoffman RM: The combination of gemcitabine and docetaxel arrests a doxorubicinresistant dedifferentiated liposarcoma in a patient-derived orthotopic xenograft model. Biomed Pharmacother 117: 109093, 2019. PMID: 31200257. DOI: 10.1016/j.biopha.2019.109093

11 Fu X, Le P, Hoffman RM: A metastatic orthotopic-transplant nude-mouse model of human patient breast cancer. Anticancer Res 13(4): 901-904, 1993. PMID: 8352558.

12 Terashima M, Sakai K, Togashi Y, Hayashi H, De Velasco MA, Tsurutani J and Nishio K: Synergistic antitumor effects of S-1 with eribulin in vitro and in vivo for triple-negative breast cancer cell lines. Springerplus 3: 417, 2014. PMID: 25140293. DOI: 10.1186/2193-1801-3-417

13 Ito K, Hamamichi S, Abe T, Akagi T, Shirota H, Kawano S, Asano M, Asano O, Yokoi A, Matsui J, Umeda IO and Fujii H: Antitumor effects of eribulin depend on modulation of the tumor microenvironment by vascular remodeling in mouse models. Cancer Sci 108(11): 2273-80, 2017. PMID: 28869796. DOI: $10.1111 /$ cas.13392

14 Kaufman PA, Awada A, Twelves C, Yelle L, Perez EA, Velikova G, Olivo MS, He Y, Dutcus CE and Cortes J: Phase III openlabel randomized study of eribulin mesylate versus capecitabine in patients with locally advanced or metastatic breast cancer previously treated with an anthracycline and a taxane. J Clin Oncol 33(6): 594-601, 2015. PMID: 25605862. DOI: 10.1200/ JCO.2013.52.4892

15 Yardley DA, Shipley D, Zubkus J, Wright GL, Ward PJ, Mani A, Shastry M, Finney L, DeBusk L and Hainsworth JD: A randomized phase II study of eribulin/cyclophosphamide or docetaxel/cyclophosphamide as neoadjuvant therapy in operable HER2-negative breast cancer. Clin Breast Cancer 19(1): 1-9, 2019. PMID: 30245148. DOI: 10.1016/j.clbc.2018.08.006

16 Di Cosimo S, La Verde N, Moretti A, Cazzaniga ME, Generali D, Bianchi GV, Mariani L, Torri V, Crippa F, Paolini B, Scaperrotta G, De Santis MC, Di Nicola M, Apolone G, Gulino A, Tripodo C, Colombo MP, Folli and de Braud F: Neoadjuvant 
eribulin mesylate following anthracycline and taxane in triple negative breast cancer: Results from the HOPE study. PLoS One 14(8): e0220644, 2019. PMID: 31390375 . DOI: 10.1371/journal. pone. 0220644

17 Yardley DA, Peacock N, Daniel B, Anz B, Molthrop DC Jr, Shroff SK, Young R, Jankov A, Vander Woude A, Shastry M, Pasek J, DeBusk LM and Hainsworth JD: Phase II trial of eribulin in patients who do not achieve pathologic complete response (pCR) following neoadjuvant chemotherapy. Breast Cancer Res Treat 180(3): 647-655, 2020. PMID: 32060783. DOI: $10.1007 / \mathrm{s} 10549-020-05563-\mathrm{z}$

18 DeRose YS, Wang G, Lin YC, Bernard PS, Buys SS, Ebbert MT, Factor R, Matsen C, Milash BA, Nelson E, Neumayer L, Randall RL, Stijleman IJ, Welm BE and Welm AL: Tumor grafts derived from women with breast cancer authentically reflect tumor pathology, growth, metastasis and disease outcomes. Nat Med 17(11): 1514-1520, 2011. PMID: 22019887. DOI: 10.1038/nm.2454

19. Hoffman RM: Patient-derived orthotopic xenografts: better mimic of metastasis than subcutaneous xenografts. Nat Rev Cancer 15(8): 451-452, 2015. PMID: 26422835. DOI: $10.1038 / \mathrm{nrc} 3972$
20 Hoffman RM: Orthotopic metastatic mouse models for anticancer drug discovery and evaluation: a bridge to the clinic. Invest New Drugs 17(4): 343-359, 1999. PMID: 10759402. DOI: $10.1023 / \mathrm{a}: 1006326203858$

21 Hoffman RM: Orthotopic is orthodox: why are orthotopictransplant metastatic models different from all other models? J Cell Biochem 56(1): 1-3, 1994. PMID: 7806583. DOI: .240560102

22 Yang M, Reynoso J, Bouvet M and Hoffman RM: A transgenic red fluorescent protein-expressing nude mouse for color-coded imaging of the tumor microenvironment. J Cell Biochem 106(2): 279-84, 2009. PMID: 19097136. DOI: 10.1002/jcb.21999

Received March 24, 2020

Revised April 5, 2020

Accepted April 6, 2020 